\title{
Parents' experiences with requesting carrier testing for their unaffected children
}

\author{
Danya F. Vears, M Genet Couns, PhD ${ }^{1,2,3}$, Clare Delany, M. Physio, PhD ${ }^{4,5}$, \\ John Massie, FRACP, PhD ${ }^{3,4,6,7}$ and Lynn Gillam, MA, PhD ${ }^{1,4}$
}

\begin{abstract}
Purpose: International guidelines generally recommend delaying genetic carrier testing in children until the child reaches the age of majority or is mature enough to be involved in the decision. Several studies have shown that carrier testing of children does occur in some instances, particularly in siblings of a child affected with a genetic condition. However, little research has explored parents' experiences with the testing process, the impact of knowing a child's carrier status, and whether parents communicate carrier information to their children.
\end{abstract}

Methods: Semistructured interviews were conducted with 33 parents of children who had one of three genetic conditions (cystic fibrosis, hemophilia, and Duchenne muscular dystrophy). Inductive content analysis was used to analyze the data.
Results: Eight distinct pathways to carrier testing were distinguishable. While some parents had requested testing, others had been offered testing and some had received carrier results incidentally following testing to exclude affected status. Some parents were discouraged from testing, which led to frustration. Overall, $67 \%$ of the parents had received carrier results for at least one child, and parents were happy to have results, even if their children were carriers.

Conclusion: Despite recommendations against carrier testing, this study provides evidence of varying practices and highlights a need to review the guidelines.

Genet Med advance online publication 24 March 2016

Key Words: carrier testing; children; genetic counseling; genetic testing

\section{INTRODUCTION}

Some parents are interested in having carrier testing for autosomal recessive and $\mathrm{X}$-linked genetic conditions performed for their other children following the diagnosis of an affected child. ${ }^{1-5}$ However, the majority of international guidelines addressing carrier testing in minors recommend against testing when there is no medical benefit. ${ }^{6-10}$ These guidelines generally suggest that testing be postponed until the child can consent to testing to protect the psychosocial well-being and future autonomy of the child. ${ }^{7,11}$ Although the recommendations by professional bodies have remained relatively consistent, they have become more nuanced, with some revised guidelines placing less importance on preserving the child's autonomy., ${ }^{9,12}$

In some cases, carrier testing is carried out for the sibling of an affected child despite the recommendations. ${ }^{1,13-19}$ Studies reporting carrier-testing practices of health professionals indicate that genetic health professionals are willing to facilitate carrier testing for autosomal recessive and X-linked conditions in unaffected children to varying degrees. ${ }^{13-16,20}$ For example, in an interview-based study of 17 key informant genetic health professionals in Australia, we found that all our participants initially recommended against carrier testing in children following parental requests, with some preemptively discussing it as a test they generally do not perform. ${ }^{13}$ However, although some participants said they never facilitate carrier testing in children younger than age 16 years, others allow parents who persist with their request to have their child tested. ${ }^{13}$ This is in contrast to a recent United Kingdom-based study in which 16 of the 25 health professionals interviewed (64\%) recommended that parents have carrier testing performed in older siblings following the diagnosis of a child with sickle cell disease, with only 6 discouraging testing. ${ }^{20}$

Although there has been some exploration of parents' perspectives on receiving carrier results as an incidental finding from newborn screening, ${ }^{21-23}$ few studies have explored parents perspectives on carrier testing for their other children following the diagnosis of an affected child. ${ }^{1,17-19}$ Although existing studies provide further evidence that some unaffected siblings receive carrier testing, little research has explored parents' experiences with the request-to-test process, the impact of knowing a child's carrier status, and whether parents communicate carrier information to their children.

To ensure that guidelines for genetics health practice are family-centered and represent the experience and needs of parents and families affected by a genetic condition, examining and documenting parents' experiences and perspectives

${ }^{1}$ Centre for Health Equity, Melbourne School of Population and Global Health, University of Melbourne, Parkville, Australia; ${ }^{2}$ Department of Public Health and Primary Care, Center for Biomedical Ethics and Law, KU Leuven, Leuven, Belgium; ${ }^{3}$ Murdoch Childrens Research Institute, Parkville, Australia; ${ }^{4}$ Children's Bioethics Centre, Royal Children's Hospital, Parkville, Australia; ${ }^{5}$ Department of Medical Education, Melbourne Medical School, University of Melbourne, Parkville, Australia; ${ }^{6}$ Department of Respiratory Medicine, Royal Children’s Hospital, Parkville, Australia; ${ }^{7}$ Department of Paediatrics, University of Melbourne, Parkville, Australia. Correspondence: Danya F. Vears (danya.vears@kuleuven.be) 


\section{ORIGINAL RESEARCH ARTICLE}

provide important empirical data. This research addresses this knowledge gap by reporting the results of interviews with parents of children with a genetic condition who had been interested in having carrier testing performed in their unaffected children. In this article, we present parents' varied experiences with requesting or receiving carrier testing for their children, their reflections on the impact of results if testing occurred, and whether they had communicated that information to their children.

\section{MATERIALS AND METHODS}

This study used qualitative methods to explore parents' experiences relating to carrier testing for their unaffected children. Parents were recruited purposively through three genetic services in three Australian States. Parents were eligible for inclusion if they had: a child with cystic fibrosis (CF), Duchenne muscular dystrophy (DMD) or hemophilia; had unaffected children who could be carriers; and had been interested in knowing the carrier status of their other children. Participants were interviewed by telephone using a semistructured interview guide that asked about their experiences with requesting and/or receiving carrier testing for their unaffected children.

Interviews were audiorecorded, transcribed verbatim, and analyzed using inductive content analysis in which content categories were derived from the data rather than predetermined. ${ }^{24-26}$ Each transcript was coded into broad content categories. Sections of the data within the broad categories were compared, and more specific subcategories were developed. All interviews were coded by DV; LG and CD coded a subset to confirm the coding scheme.

Informed consent was obtained from all participants. This study was approved by the Human Research Ethics Committees at the Royal Children's Hospital, Victoria (ID 33040A); the Hunter New England Local Health District, New South Wales (ID 13/08/21/5.12); and the Women's and Children's Hospital, South Australia (HREC/12/WCHN/114 and SSA/13/WCHN 130).

\section{Parent characteristics}

\section{RESULTS}

Thirty-two semistructured interviews were conducted with 33 parents of children with CF $(n=19)$, hemophilia $(n=10)$, or $\operatorname{DMD}(n=3)$. One interview was conducted with both parents. Participants were aged between 26 and 51 years, and 31 of 33 (94\%) were mothers. The 32 families had a combined total of 84 children. Thirty-eight of these children were affected by a genetic condition (1-3 affected children per family). Of the remaining 46 unaffected children, 45 were potential carriers. One child was an unaffected male in a family with DMD. Interviews were conducted 2.5-21 years after the diagnosis of the first affected child in the core family (mean $=6.5$ years).

\section{Pathways of carrier testing in children}

Parents reported a range of experiences; eight distinct pathways were distinguishable (Figure 1). Pathways diverged at three points: the "request phase," the "testing phase," and the "results phase." Data analysis showed no discernible differences between responses of parents of children with an autosomal recessive condition (CF) and an X-linked condition (hemophilia and DMD), even though this might have been expected. The information shown below each representative quote from the responses is formatted as follows:

Participant pseudonym: condition: whether children received testing: ages at which children were tested: children's carrier status

\section{Request phase}

In 14 of the 32 families, the parents had inquired about or requested carrier testing for their other children (pathways 1 and 2). Most parents reported that they had asked about testing around the time of the diagnosis of their affected child. Seven of the 32 families had been offered the option of having carrier testing in their other child or children by a genetic counselor or a member of the treating team rather than requesting testing (pathways 3 and 4).

The remaining 11 parents (pathways 5-8) had neither been offered nor requested carrier testing. Two parents (pathway 5) expressed a desire for testing during the interview, but they had previously been told by a health professional that carrier testing would not be performed until their child was older and had simply accepted that at the time. In the children of the other nine parents, testing had been performed as part of investigations to determine whether their child (pathways 6 and 7) or fetus (pathway 8) was affected, so carrier results were essentially an incidental finding that emerged during the process of testing for affected status.

\section{Testing phase}

Of the 45 unaffected potential carriers across the 32 families, 30 had received carrier testing (67\%), equating to 22 of 33 (67\%) parents having received carrier testing in at least one unaffected child. Overall, carrier testing took place prenatally in 7 of 30 (23\%) and in childhood in 23 of 30 (77\%). Of the 23 children tested in childhood, 11 (48\%) had blood drawn and 12 (52\%) had testing performed using the blood from their stored newborn screening card.

For the 7 parents who requested and received testing (pathway 2), the mean age at which testing took place in their children was 7.5 years (range $0-16$ years), with one parent specifically requesting to know the carrier result of the fetus after prenatal testing. For the six parents who were offered and received testing (pathway 3), the mean age at which testing took place in their children was 1.5 years (range $0-7$ years), with two parents offered carrier results prenatally.

Carrier testing identified 15 carriers and 12 noncarriers (see Table 1). For three children from one family, results were unknown because testing had been performed on stored blood spots to exclude affected status (pathway 6) and the parents were informed the child was unaffected, but the carrier results 

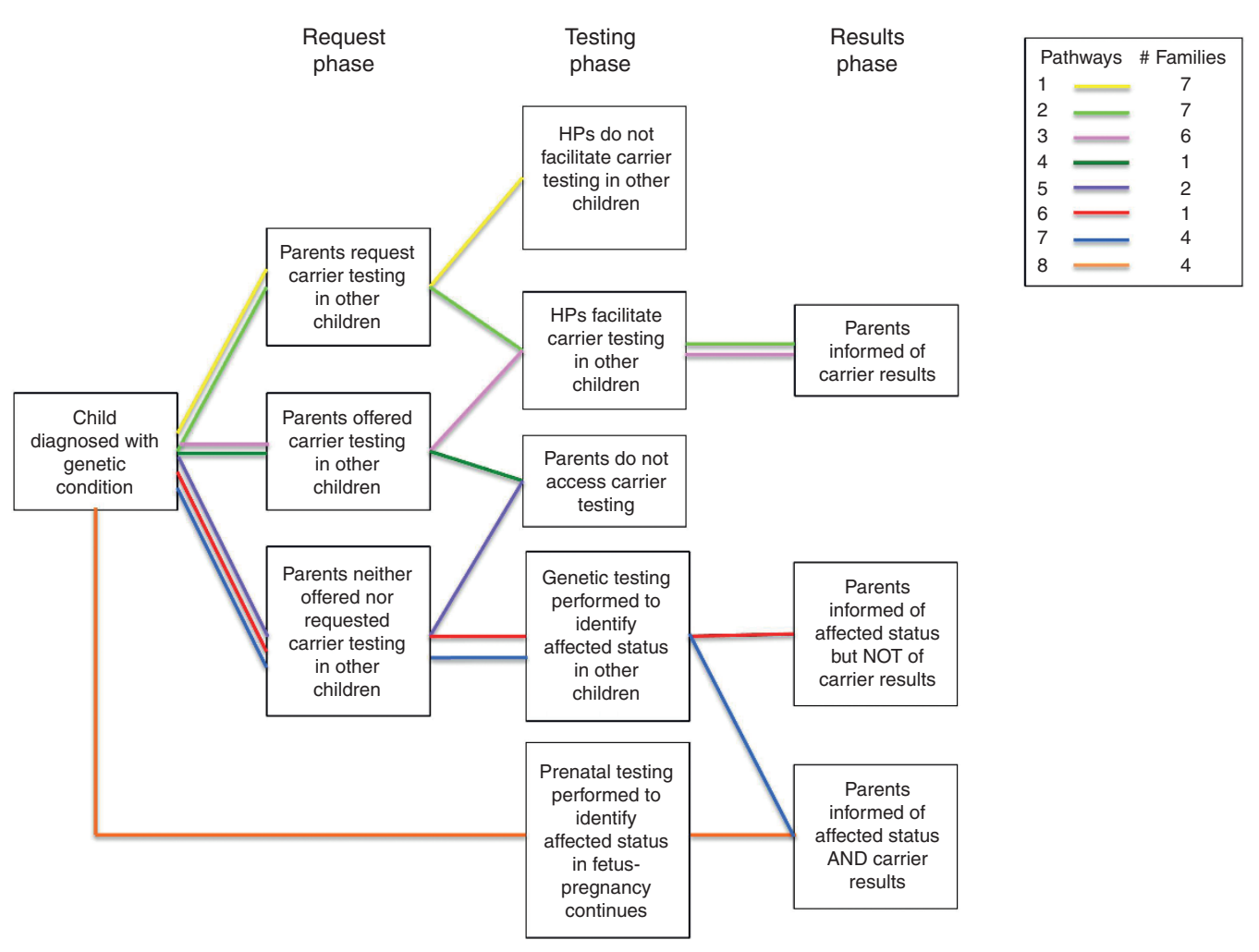

Figure 1 Pathways of carrier testing experienced by parents.

Table 1 Results for children who underwent carrier testing

\begin{tabular}{lcccc} 
Condition & Number (\%) & Carriers & Noncarriers & Unknown \\
\hline Cystic fibrosis & $21(70)$ & 9 & 9 & 3 \\
Hemophilia & $5(17)$ & 2 & 3 & 0 \\
$\begin{array}{l}\text { Duchenne muscular } \\
\text { dystrophy }\end{array}$ & $4(13)$ & 4 & 0 & 0 \\
Total & $30(100)$ & 15 & 12 & 3 \\
\hline
\end{tabular}

aResults were unknown because testing had been performed on stored blood spots to exclude affected status and although the parents were informed that the child was unaffected, the carrier results were held by the genetic service to be disclosed when the children are older.

were being held by the genetic service until the children were older, which the parents accepted.

Within pathway 2, three parents reported being encouraged to postpone testing in their children and having to convince health-care staff to allow testing to take place. The experiences of these parents varied. One parent expressed gratitude that she had not needed to be too persistent.

I think I had spoken to [name of treating doctor] about it a couple of times asking him if I could or whether or not it was important. And he sort of said, well, at the moment I don't think it's a necessity...but he was quite obliging I s'pose to me at the time after [child with haemophilia] had been so sick... which I'm sort of thankful for because I don't think I would have liked to have to argue it.

Alyssa: HA: Tested: 4y and 6y: Noncarriers
The second parent explained her frustration at needing to circumvent the nurse on the treating team, seeking the authority of the treating clinician for testing after repeated refusals.

I kind of went over their head, and at the next appointment that we actually saw the doctor I brought it up and he was fine with it. He didn't have an issue but the nurse really did have an issue with it, so she was kind of pushing us back to wait. I mean when you're told you have to wait 10 years to find out something about your kid that's already written in their blood work!

Violet: HA: Tested: 3y: Carrier

The final parent had been required to present her case in front of the hospital ethics committee before testing would be facilitated. For these parents, being told they were not allowed access to information about their child was not in line with their rights as a parent.

I think as a parent you [pause] it's your child [chuckle]. You're the guardian. You get to decide what that child learns or doesn't learn, or what they can or can't do. And then when someone says no, you can't do that, that's not your decision, you're sort of like, you're taken aback thinking, well, this is my child, I have the right to work out whether what's right and what's wrong.

Felicity: DMD: Tested: 3.5y and 3y: Carriers 


\section{ORIGINAL RESEARCH ARTICLE}

Although all three parents eventually received testing, they had felt they were fighting to get access to information about their children.

\section{Results phase}

Some, but not all, parents who requested carrier testing for their other children received testing. By contrast, some parents who did not specifically request to know the carrier status of their children were told the results. Responses of parents within these pathways are described.

\section{Parents who requested and received testing (pathways 2 and 3)}

Most parents expressed satisfaction or relief at receiving their children's results. Although a greater number of parents in this group found out their children were noncarriers rather than carriers, some explained that they were relieved to receive confirmation their children were not affected with the genetic condition in the family, regardless of carrier status.

We had him pretty close to [name of child with CF] so I guess we were still reeling a bit from that. So it was good news, we were quite happy...mainly that he didn't have CF I guess. I'm a carrier and I'm fine. So yeah, it wouldn't have been a big problem if he'd been a carrier really but it's a bonus that he's not.

Kristy: CF: Tested: Prenatal: Noncarrier

Several parents who had been told their children were carriers said the news had not come as a shock to them and was not really a concern.

I think [name of child with hemophilia] was a shock because, you know, there was no hemophilia in the family. But with [sibling] it was just sort of a bit like saying, oh well, she's got blue eyes or she's got brown hair...it wasn't a shock or a big deal, or we weren't upset about it at all. It was just, that's the way she is sort of thing.

Samantha: HA: Tested: 1y: Carrier

Several parents explained that, although they had been upset at finding out that their child was a carrier, they were pleased that testing had been performed because the certainty gave them peace of mind.

Yeah, I think it was a disappointment. But there was a 50/50 chance... it wasn't easy to take but...it was final. We know what the result is. We know the circumstances. We know what the future means.

Felicity: DMD: Tested: 3.5y and 3y: Carriers

When asked, several parents said knowing their child's carrier status had not been of any use to them so far. However, some felt it would be helpful later, particularly so that their children could be aware of their reproductive risks. One parent explained how she found it empowering to have knowledge about her child and that it would help her communicate the information to her child.

It's certainly been of no use to him, obviously. He's only 5 . But to me, I like having the knowledge in the back of my head. I think knowledge is power and you can make your decisions later on in life on how you broach the subject with him.

Trudy: CF: Tested: Carrier

Parents felt that knowing their child's carrier status had not made them view their child any differently or treat them in a negative way.

\section{Parents who requested but did not receive testing (pathway 1)}

For seven families, testing had not been facilitated following their request. Parents reported being told that it was best to wait until the child is old enough to make the decision themselves, with the health professional often suggesting ages at which testing might be appropriate. Some health professionals had explained that testing was unnecessary because there were no implications for the child at that time. Several parents recalled the health professionals mentioning concepts such as consent, with one explaining it had been discussed as a requirement for testing.

I think we actually asked if we could have her genetically tested to see if she was a carrier and we were told no, that she would have to give permission herself to have that done and she couldn't do that until she was, I don't know, 15 or 16 or something.

Jessica: HA: Not tested

The majority of parents who were denied testing said they accepted that testing should be delayed or could understand why testing had not been performed. One parent reiterated that it was unnecessary, and another mentioned the child's right to privacy. Despite appreciating the reasons for delaying testing, some parents still felt it would be good to know their child's carrier status.

Others were not as accepting of the decision not to test their children, disagreeing with health professionals' reasoning. One parent who felt that the refusal of the health professionals to test was "somewhat ridiculous" explained that she planned to re-request next time her child had an appointment.

\section{Parents who received carrier results incidentally (pathways 7 and 8)}

For 8 of 32 parents (25\%), genetic testing had been performed to exclude affected status in their child either prenatally $(n=4)$ or after birth $(n=4)$. These parents had not specifically asked to know the carrier status of their fetus or child, and many had not expected they would be told this information. Some thought 
they had not been informed that carrier testing was taking place, and others acknowledged they may have been told but this had not been their focus at the time.

No, to be honest I didn't know they were going to tell me that. I found it interesting information when they did tell me that. But at that point, all I wanted to hear was that no, he didn't have CF. So everything else was a bit of a side issue.

Trudy: CF: Tested: Birth: Carrier

Information regarding the child's carrier status and the presence or absence of CF was often bundled together by the health professionals. Parents who found out incidentally that their child did not carry a mutation explained the additional relief this provided. By contrast, some parents who were told that their child was a carrier experienced mixed emotions.

So she rang me with the results and yeah, I was gobsmacked that she wasn't even a carrier!

Prue: CF: Tested: Prenatal: Noncarrier

I think I was a little bit taken aback because when they said no to the CF, I was, like, great! That's fantastic! But he is a carrier. Oh, OK. Well, at least he's not got CF.

Trudy: CF: Tested: Birth: Carrier

Some parents felt that they would have asked for this information regardless, although perhaps later. Others were pleased they knew their child's carrier status but questioned whether they would have asked for testing if they had not found out incidentally.

We've talked about it a lot... Had that initial sweat test not [been ambiguous], I think we would have left finding out for them. Because being a carrier ultimately is not going to affect their life unless they have children with someone who is a carrier as well. And then that needs to be their decision when they're old enough to make that decision, really.

Rachel: CF: Tested: 3.5y and 3.5y: Noncarriers

\section{DISCUSSION}

This is the first study to report the pathways of parents' experiences with carrier testing in their unaffected children following the diagnosis of a child with a genetic condition. We have shown that, in line with genetic health professionals' reports, some children in Australia do receive carrier testing. ${ }^{13}$ This is consistent with our previous study of Australian genetic health professionals, some of whom reported providing carrier testing. ${ }^{13}$ Despite our purposive sampling for parents who wanted to know their child's carrier status, we found that a similar proportion of parents in our study $(67 \%)$ had received carrier testing for at least 1 of their children compared with a cohort of 75 parents of children with fragile X syndrome in which $60.7 \%$ of their children had been tested. ${ }^{19}$ Although other studies have reported lower rates of testing in siblings of children with CF, spinal muscular atrophy, and mucopolysaccharidosis, for which 33,16 , and 39\% of parents, respectively, had received carrier testing for their children, ${ }^{1,17,18}$ they provide further evidence that despite the recommendations a considerable proportion of parents receive carrier testing for their children. Studies in other areas of pediatric practice have highlighted the importance of exploring parents' experiences relating to the care of their children. ${ }^{27,28}$ Incorporation of their perspectives ensures that practices continue to meet the needs of the pediatric patient and their family rather than relying on the health professionals' views and assessments.

The interviews elucidated that carrier information may be identified incidentally in childhood or prenatally as a by-product of genetic testing to exclude affected status in a sibling. Some parents were informed about the carrier status of their children when they had not specifically asked for this information, which seems in direct contrast with genetic health professionals' refusals to provide testing to parents who specifically asked to know their child's carrier status. Although most of the parents in the former group indicated that they were pleased they had received this information, some reported that they had not realized carrier testing was taking place. Although this does not necessarily mean that this was not discussed with the parents in genetic counseling sessions, it does indicate that they were not given the option to actively choose whether they wanted to know this genetic information about their child. This is important given that one mother questioned whether she would have elected to find out the CF carrier status of her children had she been given the choice, and others have reported parents who supported delaying carrier testing in order to respect the autonomy of their children. ${ }^{2}$

As one might expect, parents who were told their children were not carriers were relieved. However, some parents of children with CF who learned that their child was a carrier were also relieved, because, for these parents, this information was imparted in the context of their child being cleared of actually having CF. Likewise, parents in this study were not concerned that knowing their child's carrier status would negatively alter the way they viewed or treated their child. Their perception corresponds with that of parents in other studies, some of whom knew their child's carrier status. ${ }^{1,19}$ This is contrary to the common assumption in the literature and professional guidelines that parents' perceptions of their children based on their carrier status may be harmful for the child. ${ }^{10,16,29-31}$ These findings provide insight into the seemingly benign nature of their child's carrier status, in contrast to the possible outcome that their child had a life-threatening condition. These parents' relief may have been enhanced because they had the experience of parenting an affected child and are well informed about the condition. In addition, because all the parents are carriers themselves, they have a good appreciation of the lack of health implications associated with their child's carrier status. Therefore, finding out their child's carrier status for CF was not a major concern. 


\section{ORIGINAL RESEARCH ARTICLE}

Although some parents said they accepted health professionals' recommendations to postpone carrier testing in their children and could understand why testing was "unnecessary," others were less acquiescent. Several parents said that, as parents, they have a right to information about their children and are therefore entitled to know their carrier status. This has also been reported in other studies. ${ }^{2,19}$ However, in the current study, only parents who had initially been told they could not have testing made this point. The language these parents used suggests that they felt their rights had been challenged, which prompted them to adopt a combative stance in order to fight to regain the right to make decisions for their children. This suggests that outright denial of parents' requests for carrier testing for their children may have negative consequences, setting them on a path of conflict with health professionals. This may negatively impact the clinical relationship between the genetic health professional and the parents, which may have repercussions for the children's health if the family then decided to break ties with the treating team, or for the children when they reached adolescence and wanted more information about their risks or reproductive options.

There are several limitations of this study. Because we purposively recruited parents based on their interest in knowing their child's carrier status, and with a range of testing experiences, the proportion of parents in our study who received testing for their children may be higher than in the population of affected families more broadly. Although this study does not show the frequency of carrier testing in the population, it does provide clear evidence that, despite the current guidelines, some parents do receive carrier testing for their unaffected children in the context of having a child with a genetic condition. In addition, our sample consists mostly of mothers; however, we did not get a sense that the fathers had contradicting views. Also, for a small number of participants, the diagnosis of their affected child had taken place many years prior, which may alter their recall of the experience.

\section{Conclusions}

We identified discrepancies in parents' access to carrier testing in their children, which raises the question of equity. Apparent lack of equity in access to a health-care service is, in principle, ethically problematic, so further investigation is warranted to determine whether ethically unjustified inequity of access is occurring.

The findings related to incidental carrier status results also raise significant questions. Although this study focused on parents who wanted to know their child's carrier status, it also showed we cannot presume that all parents want this information. Disclosing carrier information without exploring their preferences removes their ability to make decisions about what they consider to be in their child's best interests. Although it is not likely to cause significant harm for parents or their children if this information is disclosed, we take the view that parents should be presented with the option of deciding whether they want to know their child's status when it is identified incidentally. We do not regard it as contentious to argue that parents should be given an option not to receive an incidental carrier status finding, especially when many in the field believe that no carrier-status information should be available to parents. To take the argument one step further (a step that is more controversial), it could be argued that if parents are given incidental carrier results for their child when they are not actively seeking it, then there is little reason to withhold testing from parents who specifically request carrier testing in their children. Although we acknowledge that carrier testing may not always be appropriate, for the ethical principle of equity to be given due regard, we suggest that all parents be offered the option of learning their child's carrier results unless there are compelling ethical reasons specific to an unusual situation in that particular family. Whether or not carrier testing should take place can then be discussed between the parents and the genetic health professionals to make the best decision on the basis of individual circumstances.

\section{ACKNOWLEDGMENTS}

D.F.V. acknowledges the support of the Brocher Foundation (Geneva, Switzerland), the Research Fund Flanders (Belgium), and the Ministère de l'Économie, de l'Innovation et des Exportations du Québec, PSR-SIIRI-850 (Canada).

\section{DISCLOSURE}

The authors declare no conflict of interest.

\section{REFERENCES}

1. Balfour-Lynn I, Madge S, Dinwiddie R. Testing carrier status in siblings of patients with cystic fibrosis. Arch Dis Child 1995;72:167-168.

2. Barnes $C$. Testing children for balanced chromosomal translocations: parental views and experiences. In: Clarke AJ (ed). The Genetic Testing of Children. BIOS Scientific Publishers: Oxford, UK, 1998:51-60.

3. Fanos JH, Mackintosh MA. Never again joy without sorrow: the effect on parents of a child with ataxia-telangiectasia. Am J Med Genet 1999;87: 413-419.

4. Brunger JW, Murray GS, O'Riordan M, Matthews AL, Smith RJ, Robin NH. Parental attitudes toward genetic testing for pediatric deafness. Am J Hum Genet 2000;67:1621-1625.

5. Kaneko M, Ohashi H, Takamura T, Kawame H. Psychosocial responses to being identified as a balanced chromosomal translocation carrier: a qualitative investigation of parents in Japan. J Genet Couns 2015;24:922-930.

6. Human Genetic Society of Australasia. Process of Genetic Counselling. 2008. https://www.hgsa.org.au/documents/item/13. Accessed 13 November 2015.

7. Borry P, Fryns JP, Schotsmans P, Dierickx K. Carrier testing in minors: a systematic review of guidelines and position papers. Eur J Hum Genet 2006;14:133-138.

8. Botkin JR, Belmont JW, Berg JS, et al. Points to consider: ethical, legal, and psychosocial implications of genetic testing in children and adolescents. Am J Hum Genet 2015;97:6-21.

9. Lucassen A, Clancy T, Montgomery J, et al. Report on the Genetic Testing of Children. British Society for Human Genetics: Birmingham, UK, 2010.

10. Ross LF, Ross LF, Saal HM, David KL, Anderson RR; American Academy of Pediatrics; American College of Medical Genetics and Genomics. Technical report: ethical and policy issues in genetic testing and screening of children. Genet Med 2013;15:234-245.

11. Borry P, Evers-Kiebooms G, Cornel MC, Clarke A, Dierickx K; Public and Professional Policy Committee (PPPC) of the European Society of Human Genetics (ESHG). Genetic testing in asymptomatic minors: background considerations towards ESHG recommendations. Eur J Hum Genet 2009;17:711-719.

12. British Medical Association Ethics Department. Medical Ethics Today: The BMA's Handbook of Ethics and Law, 3rd edn. Wiley-Blackwell: West Sussex, UK, 2012.

13. Vears DF, Delany C, Gillam L. Carrier testing in children: exploration of genetic health professionals' practices in Australia. Genet Med 2015;17:380-385. 
14. Fryer A. Inappropriate genetic testing of children. Arch Dis Child 2000;83:283-285.

15. Multhaupt-Buell TJ, Lovell A, Mills L, Stanford KE, Hopkin RJ. Genetic service providers' practices and attitudes regarding adolescent genetic testing for carrier status. Genet Med 2007;9:101-107.

16. Borry P, Goffin T, Nys H, Dierickx K. Attitudes regarding carrier testing in incompetent children: a survey of European clinical geneticists. Eur J Hum Genet 2007; 15:1211-1217.

17. Lavery C. On the receiving end of medicine. In: Clarke AJ (ed) The Genetic Testing of Children. BIOS Scientific Publishers: Oxford, UK, 1998.

18. Meldrum C, Scott C, Swoboda KJ. Spinal muscular atrophy genetic counseling access and genetic knowledge: parents' perspectives. J Child Neurol 2007;22:1019-1026

19. McConkie-Rosell A, Spiridigliozzi GA, Rounds K, et al. Parental attitudes regarding carrier testing in children at risk for fragile $X$ syndrome. Am J Med Genet 1999;82:206-211.

20. Noke M, Peters S, Wearden A, Ulph F. A qualitative study to explore how professionals in the United Kingdom make decisions to test children for a sickle cell carrier status. Eur J Hum Genet 2016:24:164-170.

21. Lewis S, Curnow L, Ross M, Massie J. Parental attitudes to the identification of their infants as carriers of cystic fibrosis by newborn screening. J Paediatr Child Health 2006;42:533-537.

22. Ulph F, Cullinan T, Qureshi N, Kai J. Parents' responses to receiving sickle cell or cystic fibrosis carrier results for their child following newborn screening. Eur J Hum Genet 2015;23:459-465.
23. Kai J, Ulph F, Cullinan T, Qureshi N. Communication of carrier status information following universal newborn screening for sickle cell disorders and cystic fibrosis: qualitative study of experience and practice. Health Technol Assess 2009;13:1-82, iii.

24. Schamber L. Time-line interviews and inductive content analysis: their effectiveness for exploring cognitive behaviors. J Am Soc Inf Sci 2000;51: 734-744.

25. Downe-Wamboldt B. Content analysis: method, applications, and issues. Health Care Women Int 1992;13:313-321.

26. Graneheim UH, Lundman B. Qualitative content analysis in nursing research: concepts, procedures and measures to achieve trustworthiness. Nurse Educ Today 2004;24:105-112.

27. Garwick AW, Kohrman C, Wolman C, Blum RW. Families' recommendations for improving services for children with chronic conditions. Arch Pediatr Adolesc Med 1998; 152:440-448.

28. Homer CJ, Marino B, Cleary PD, et al. Quality of care at a children's hospital: the parent's perspective. Arch Pediatr Adolesc Med 1999;153:1123-1129.

29. Nelson RM, Botkin JR, Kodish ED, et al. Ethical issues with genetic testing in pediatrics. Pediatrics 2001;107:1451-1455.

30. Clarke A. The genetic testing of children. J Med Genet 1995:32:492.

31. American Society of Human Genetics Board of Directors, American College of Medical Genetics Board of Directors. Points to consider: ethical, legal, and psychosocial implications of genetic testing in children and adolescents. Am J Hum Genet 1995:57:1233-1241. 